\title{
No Observable Effect Level
}

National Cancer Institute

\section{Source}

National Cancer Institute. No Observable Effect Level. NCI Thesaurus. Code C156651.

The greatest amount, or highest dose or exposure level, of a substance that produces no noticeable toxicity. 